\title{
Industrial Transfer under Synergy Development Analysis between Key Industries and Logistics Capability
}

\author{
Yude He \\ School of Economic and Management, Southwest Jiaotong University, Chengdu, China \\ Email: heyude2012@163.com
}

Received 22 May 2015; accepted 25 January 2016; published 28 January 2016

Copyright (C) 2016 by author and Scientific Research Publishing Inc.

This work is licensed under the Creative Commons Attribution International License (CC BY). http://creativecommons.org/licenses/by/4.0/

cC) (7) Open Access

\begin{abstract}
There are new changes and features existing in the regional logistics system and regional economic system under the background of industrial transfer. On one hand, the two influence each other. On the other hand, the two also adapt to each other. From the organizational perspective of synergetic theory, the research regards the regional logistics system and regional economic system as a whole system, which is the regional coordinated development system under the background of industrial transfer, in order to build the evaluation index and model of collaborative development of collaborative development. Then this research did empirical study to examine the development of five dominant industries with logistics industry in Sichuan Province from 2003 to 2013. The results indicate that the degree of synergism system rises with continuous integration and conflicts, while the overall degree is still low. Therefore, the local government should provide strong support for the coordinated development of regional logistics and regional economy.
\end{abstract}

\section{Keywords}

Industrial Transfer, Regional Logistics, Regional Economy, Synergy Degree

\section{Introduction}

Due to the international and domestic industrial division adjustment, China's eastern coastal areas in central and western regions speed up the transfer of industries. In the Guiding Opinions on Midwest undertaking industrial transfer issued by China's State Council in 2010, collaborative relationship between industrial development and logistics capabilities has been greatly different under industrial transfer. It is significant to analyze the degree of adaptation of industrial development and logistics capability under the new situation, and the objective evalua- 
tion of regional logistics development status, in order to promote the coordinated development of logistics and regional economy.

Industrial transfer theory began in the 1930s of the last century, including such classic theory: Japanese scholars Akamatsu [1] proposed flying geese pattern; American scholar Raymond Vernon [2] proposed the product life cycle model; Kojima [3] proposed transfer theory of marginal industries. These three theories have some degree of inheritance, and from the industrial level, the product cycle and comparative advantage analysis of industrial transfer motivation, analyze the economic impact of industrial transfer.

For the relationship between logistics and industry, someone using Incheon International Airport as the research object, analyzed the development strategy of the airport, and proposed that as a logistics center in Northeast Asia it should enhance the selective competitiveness and development. Someone established a framework for investment in the economic evaluation of transport investments, pointing out the construction of logistics promoting economic development.

Kajal pointed out the important role of logistics capabilities in the industrial cycle. In order to assess the current situation and forecast logistics capability in future, a system of economic indicators logistics through rigorous statistical procedures is established. Arvis and Mustra [4] with the increase in global production sharing, the shortening of product life cycles, and the intensification of global competition, highlighted logistics as a strategic source of competitive advantage.

Christopher [5] raised the logistics and supply chain management, reduced logistics costs and improved logistics capabilities equivalent. This can improve the competitiveness of the industry. These authors have mentioned that logistics capability and industrial development have a strong correlation; however, there are still relatively few people mentioning in the industrial transfer under a new relationship between the two changes.

In the choice of evaluation methods, Hui and Dong [6] used DEA method, and sustainable development of the logistics industry to evaluate. Li [7] used econometric methods, port logistics and industrial development of Beijing quantitative analysis, and proved the correlation between them. Someone used Eview software testing by GRANGER. The results proved the causality analysis between variables of port logistics and regional economy. These scholars generally used regression methods, or statistical methods. Obviously, logistics capability and industrial development have a synergistic relationship. However, the use of collaborative model to analyze the relationship between the two is less.

In all the above, in terms of the research object, more research has been carried out between logistics capabilities and industrial development. However, there are few studies on the transfer of industries under the dynamic relationship between them. In research methods, rarely used collaborative models were applied to logistics capability and industrial development. For this reason, this article will be synergistic perspective, focuses on analyzing the trend of industrial transfer and the internal mechanism of the development of key industries and logistics capability, establishes evaluation index system and synergistic model, takes Sichuan Province as the research object, carries on the empirical analysis and puts forward suggestions based on the results of analysis of the current problems.

The paper is organized as follows. Indicators and the establishment of synergistic filtering index system model in this paper are given in the next section; statement synergistic model and empirical analysis based on data from Sichuan are given in Section 3. The results are analyzed and presented for suggestions in Section 4.

\section{Establish Indicators and Synergistic Models}

\subsection{Select the Industrial Transfer under the Industrial Development Indicators}

Many scholars have different views on how to quantify the degree and scope of industrial transfer and to establish a scientific evaluation system for industrial development. Some scholars take a single GDP as a measure of industrial development indicators [8]. Some scholars use per capita GDP, per capita disposable income, fiscal revenue, the proportion of tertiary industry and some integrated indicators to evaluate, based on the new situation of industrial transfer. This paper tends to investigate in the related fields of industry and local industry. Focuses on statistical industrial transfer in key industries and the establishment of industrial development indicators in the industry fluctuations as the core. Reference to the 2010 China's State Council issued the guidance on Midwest undertaking industrial transfer. Determine the focus shifted five industries, as follows: high-tech industries, advanced manufacturing, energy, mineral exploitation and processing industry, agro-industry, labor-intensive industries. 


\subsection{Select the Industrial Transfer under the Logistics Capabilities Indicators}

On the concept of logistics capabilities, many scholars from different angles have given different definitions. MA proposed the running logistics is a kind of comprehensive logistics capability, which is a system perspective, is from the customer needs to the whole process of accepting delivery of the customer with appropriate speed, logistics costs, order completion time, etc. And someone general believes that logistics capability that is, the ability to demand the largest body in the region to offer services. This paper argues that logistics capability first reflects a kind of ability, with export-oriented, delivery, stage and regional characteristics. Secondly, logistics capabilities for industrial development should have a stronger role in promoting and stimulating. Therefore, the regional logistics capacity in this article is: in a certain range and time, the regional logistics through rational and efficient use of system resources, logistics services in the form of industrial development, specifically show on the efficiency and cost, support capabilities, capacity development, security and innovative ability of a force formed part of the logistics operation, that is, logistics capabilities. In this paper, drawing on the basis of index system on other scholars, taking into account the operability and scientific nature of the evaluation index, select quantitative indicators which are easy to be found in the current China Statistical Yearbook, qualitative indicators partially removed. The combination of the above support, capacity development, security and innovative ability and the ability of each to quantify, is the logistics capability evaluation system (Table 1).

\subsection{Key Industries-Logistics Capability Synergy Model}

In the Synergy study, the measurement methods are mainly Synergy degree, Synergy coupling degree model, entropy equation method, interval value judgment and gray correlation model. Based on the theoretical frame-work of Synergy, Consider changes in system is the result of more than one order parameter interaction Synergy relationship between the order parameter is the key to the whole system orderly. Synergy degree is the degree of harmony between each system element in the development process, which reflects the trend of the system from disorder to order. Through Synergy effect theory, that is, Systems tend ordered not because balanced or unbalanced system is, nor is the system far from equilibrium, the key is "synergistic effect" between the internal system of interrelated subsystems. It determines the characteristics and laws of the system change. It is what we want to calculate the degree of Synergy. The key industry and logistics capabilities as two subsystems regional synergy development system, as well as by establishing key industry-logistics capabilities coordinated development evaluation model, follow these steps.

\subsubsection{Establish the Degree of Order Subsystem Model}

"The key industry-logistics capabilities" Synergy Development System refers to a certain area, key industries and logistics capabilities through the interaction and mutual influence and mutual restriction organic whole with a certain structure and function and composition. By study also found a small number of order parameter equation, we can determine the evolution of the behavior of the system. Therefore, the "regional coordinated development" complex systems: $m=f\left(l_{1}, l_{2}\right), l_{1}$ representatives of key industry development system, $l_{2}$ representatives of regional logistics capability of the system, $f$ is a composite function, Contribution to the order parameter of orderliness is efficiency coefficient (Efficacy Coefficient, EC).

Order parameter is represented by $u_{j i}$, order parameter of the system's contribution rate is represented by $E C\left(u_{j i}\right), u_{j i}$ value in the actual system performance indicators $X_{j i}(j=1,2 ; i=1,2, \cdots, n)$. Assuming the system in the evolution of the order parameter variables $u_{j}=\left(X_{j 1}, X_{j 2}, \cdots, X_{j i}\right), \beta_{j i} \leq X_{j i} \leq \alpha_{j i}, \quad i \in[1, n]$. Efficiency coefficient expression is as follows:

$$
E C\left(u_{j i}\right)=\left\{\begin{array}{l}
\frac{X_{j i}-\beta_{j i}}{\alpha_{j i}-\beta_{j i}}, i \in[1, l] \\
\frac{\alpha_{j i}-X_{j i}}{\alpha_{j i}-\beta_{j i}}, i \in[l, n]
\end{array}\right.
$$

where, $\alpha_{j i}$ and $\beta_{j i}$, respectively when the system is stable. The variable upper and lower critical point $X_{j i}$, $\beta_{j i} \leq X_{j i} \leq \alpha_{j i}$. Overall, the contribution of the order parameter $U_{j}$ system can be achieved by integrating 
Table 1. Industry and logistics systems Industrial transfer under.

\begin{tabular}{|c|c|c|c|c|}
\hline $\begin{array}{c}\text { Total } \\
\text { System }\end{array}$ & Subsystem & $\begin{array}{l}\text { Subsystem } \\
\text { order parameter }\end{array}$ & $\begin{array}{l}\text { Subsystem order parameter } \\
\text { quantitative indicators }\end{array}$ & Remark \\
\hline \multirow{23}{*}{$\begin{array}{l}\text { Industry } \\
\text { and } \\
\text { logistics } \\
\text { systems } \\
\text { Industrial } \\
\text { transfer } \\
\text { under }\end{array}$} & \multirow{11}{*}{$\begin{array}{l}\text { Key } \\
\text { industry } \\
\text { system } \\
\text { (X) }\end{array}$} & High-tech & Electronic Equipment Manufacturing (X11) & \\
\hline & & $\begin{array}{l}\text { Industry } \\
\text { (X1) }\end{array}$ & Pharmaceutical Manufacturing (X12) & $\begin{array}{l}\text { To measure the scale of } \\
\text { development of key industries, }\end{array}$ \\
\hline & & \multirow{2}{*}{$\begin{array}{c}\text { Advanced } \\
\text { Manufacturing } \\
\text { (X2) }\end{array}$} & General equipment manufacturing (X21) & the introduction of industry \\
\hline & & & Special equipment manufacturing industry (X22) & $\begin{array}{l}\text { aggregation index, the specific } \\
\text { algorithm: }\end{array}$ \\
\hline & & \multirow{3}{*}{$\begin{array}{c}\text { Development } \\
\text { of energy and } \\
\text { mineral } \\
\text { processing } \\
\text { industry (X3) }\end{array}$} & Oil and gas exploration industry (31) & $L_{i j} / \sum_{i=1}^{n} L_{i j}$ \\
\hline & & & $\begin{array}{l}\text { Ferrous metal smelting and } \\
\text { rolling processing industry (X32) }\end{array}$ & $L Q_{i j}=\frac{i m}{\sum_{j=1}^{m} L_{i j}} / \overline{\sum_{i=1}^{n} \sum_{j=1}^{m} L_{i j}}$ \\
\hline & & & $\begin{array}{l}\text { Non-ferrous metal smelting } \\
\text { and rolling processing industry (X33) }\end{array}$ & $\begin{array}{c}L Q_{i j} \text { indicate } i \text { region } j \\
\text { Industry location quotient, }\end{array}$ \\
\hline & & \multirow{2}{*}{$\begin{array}{l}\text { Agro-industry } \\
\quad \text { (X4) }\end{array}$} & Food Manufacturing (X41) & $i$ denotes $i$ region $(i=1,2, \cdots, n)$, \\
\hline & & & Beverage Manufacturing (X42) & $j$ denote $j$ sectors $(j=1,2, \cdots, m)$, \\
\hline & & \multirow{2}{*}{$\begin{array}{l}\text { Labor-intensive } \\
\text { industries (X5) }\end{array}$} & Textile, manufacturing (X51) & $\begin{array}{c}L_{i j} \text { denote } i \text { region } j \\
\text { Output of the industry. }\end{array}$ \\
\hline & & & Leather and leather products industry (X52) & \\
\hline & \multirow{12}{*}{$\begin{array}{l}\text { Logistics } \\
\text { capability } \\
\text { system } \\
\text { (Y) }\end{array}$} & \multirow{3}{*}{$\begin{array}{l}\text { Base support } \\
\text { capability (Y1) }\end{array}$} & $\begin{array}{l}\text { Logistics and construction investment } \\
\text { proportion of total investment (Y11) }\end{array}$ & $\begin{array}{l}\text { Logistics and construction } \\
\text { investment/total investment in fixed assets }\end{array}$ \\
\hline & & & $\begin{array}{l}\text { Logistics practitioners proportion } \\
\text { of total employees (Y12) }\end{array}$ & $\begin{array}{l}\text { Number of employees of the logistics } \\
\text { industry/total number of employees }\end{array}$ \\
\hline & & & Road network density (Y13) & $\begin{array}{l}\text { (Highways + Railway operating mileage } \\
\text { + Inland Waterways)/Land area }\end{array}$ \\
\hline & & \multirow{2}{*}{$\begin{array}{c}\text { Scale } \\
\text { development } \\
\text { capacity (Y2) }\end{array}$} & Per capita cargo (Y21) & Cargo/Population \\
\hline & & & Freight turnover per capita (Y22) & Freight turnover/Population \\
\hline & & \multirow{3}{*}{$\begin{array}{l}\text { Information } \\
\text { security } \\
\text { capabilities } \\
\text { (Y3) }\end{array}$} & Per capita Telecommunications Services (Y31) & $\begin{array}{l}\text { Telecommunications } \\
\text { Services/population }\end{array}$ \\
\hline & & & $\begin{array}{l}\text { Every million people has a } \\
\text { fixed telephone number (Y32) }\end{array}$ & $\begin{array}{l}\text { (Fixed telephone subscribers/population) } \\
\qquad * 10,000\end{array}$ \\
\hline & & & $\begin{array}{l}\text { Every million people have a } \\
\text { mobile phone number (Y33) }\end{array}$ & $\begin{array}{l}\text { (Mobile phone subscribers/population) } \\
\qquad * 10,000\end{array}$ \\
\hline & & \multirow{4}{*}{$\begin{array}{l}\text { Scientific and } \\
\text { technological } \\
\text { innovation } \\
\text { capability } \\
\text { (Y4) }\end{array}$} & The per capita cost of education (Y41) & Education Expenses/Population \\
\hline & & & $\begin{array}{l}\text { The number of college students } \\
\text { per million people in (Y42) }\end{array}$ & $\begin{array}{l}\text { (In the number of college } \\
\text { students/population) } * 10,000\end{array}$ \\
\hline & & & Fee per capita Science (Y43) & Science Expenses/Population \\
\hline & & & $\begin{array}{l}\text { Number of professional and technical } \\
\text { personnel per million people (Y44) }\end{array}$ & $\begin{array}{l}\text { (Number of professional and } \\
\text { technical personnel/population) * 10,000 }\end{array}$ \\
\hline
\end{tabular}

$E C\left(u_{j i}\right)$, in order to better reflect the different combinations of system data, take the linear weighted sum method to deal with, namely, the degree of order subsystem model is as follows:

$$
E C_{j}\left(u_{j}\right)=\sum_{t=1}^{n} \omega_{t} E C\left(u_{j i}\right), \omega \geq 0 \text { and } \sum_{t=1}^{n} \omega_{t}=1
$$

\subsubsection{Synergy Evaluation Model}

Synergy Model for the joint development of a quantitative description of the adaptation of the system. The order parameter as a function of the independent variables of the model. The value of this function is called system Synergy Degrees (Synergy Degree, SD). For a given initial time $t_{0}$, sub-system order parameter degree of order 
is $E C_{j}^{0}\left(u_{j}\right)$. After a certain period of time the system reaches a time point $t_{1}$, the synergy degree of this system are:

$$
S D=n \sqrt{\left|\prod_{j=1}^{2}\left[E C_{j}^{i}\left(u_{j}\right)-E C_{j}^{0}\left(u_{j}\right)\right]\right|}
$$

The system reflects the status of the synergy subsystem, synergy degree value between [0, 1], Description of composite systems with Synergy degrees. The closer the value 1, the higher the degree of synergy. Conversely lower. If a subsystem changed greatly, while the other subsystem does not change, or changes little, the whole system is not synergy state, synergy degree value between $[-1,0]$.

Actively undertake industrial transfer, is to build a modern industrial system, accelerate the transformation of economic development objective requirements. So how actively respond to the industrial transfer is an urgent and arduous task. Logistics industry as the third profit source of economic development, the development of key industries has a huge role in promoting and stimulating, while the industrial transfer of industrial structure changes will inevitably lead to a chain reaction of logistics capabilities development, Industrial transfer under the pillar industries and logistics capabilities Synergy degree evaluation. The discovery of the error has important significance in the collaborative development. Decision evaluation process is shown in Figure 1.

\section{Empirical Analysis}

\subsection{Data Acquisition Subsystem Evaluation}

This article is based on China's Sichuan province as the research object, Indicator data comes from "China Statistical Yearbook" (2000 to 2014), "Statistical Yearbook of Sichuan Province” (1999 to 2014), "China Transportation Statistics Yearbook" (2000 to 2014), “China Statistical Abstract” (2006 to 2013), "China labor Statistical Yearbook" (2003 to 2014), "China economic Census Yearbook" (2003 to 2010), "statistical Yearbook of China's tertiary industry” (2001 to 2014), "Regional economic China statistical Yearbook” (2006 to 2014) "China transportation Yearbook" (2008 to 2014).

\subsection{Data Processing Subsystem of Evaluation}

To facilitate the comparison between the data, more intuitively and accurately reflect fluctuations of the data. This paper uses the more common method of standardization, and the results of data standardization process by SPSS statistical software are shown in Table 2 and Table 3.

\subsection{Set Index Weights}

According to Equation (2), the calculated degree of order preceded the evaluation index to determine the weights,



Figure 1. Degree of order key industries and logistics capabilities. 
Table 2. Standardized numerical evaluation index system of key industries in Sichuan Province.

\begin{tabular}{cccccccccccc}
\hline year & $\mathrm{x} 11$ & $\mathrm{x} 12$ & $\mathrm{x} 21$ & $\mathrm{x} 22$ & $\mathrm{x} 31$ & $\mathrm{x} 32$ & $\mathrm{x} 33$ & $\mathrm{x} 41$ & $\mathrm{x} 42$ & $\mathrm{x} 51$ & $\mathrm{x} 52$ \\
\hline 2003 & -0.708 & -0.869 & -0.939 & -0.864 & -1.08 & -0.976 & -1.034 & -0.894 & -0.787 & -0.718 & -0.937 \\
2004 & -0.627 & -0.798 & -0.895 & -0.811 & -1.055 & -0.947 & -0.967 & -0.829 & -0.739 & -0.663 & -0.918 \\
2005 & -0.644 & -0.746 & -0.828 & -0.735 & -0.812 & -0.782 & -0.867 & -0.745 & -0.879 & -0.783 & -0.853 \\
2006 & -0.685 & -0.626 & -0.665 & -0.659 & -0.669 & -0.586 & -0.656 & -0.612 & -0.597 & -0.701 & -0.702 \\
2007 & -0.563 & -0.491 & -0.511 & -0.585 & -0.373 & -0.311 & -0.486 & -0.452 & -0.496 & -0.604 & -0.482 \\
2008 & -0.431 & -0.337 & -0.215 & -0.422 & -0.019 & -0.144 & 0.082 & -0.331 & -0.293 & -0.464 & -0.305 \\
2009 & -0.06 & 0.036 & 0.101 & 0.047 & 0.294 & 0.216 & 0.659 & -0.021 & -0.012 & -0.085 & 0.147 \\
2010 & 0.165 & 0.474 & 0.501 & 0.668 & 1.148 & 0.472 & 0.666 & 0.416 & 0.274 & 0.277 & 0.749 \\
2011 & 0.612 & 0.758 & 1.012 & 0.898 & 1.07 & 0.727 & 0.601 & 0.779 & 0.703 & 0.928 & 1.163 \\
2012 & 1.165 & 1.194 & 1.653 & 1.281 & 1.638 & 1.139 & 1.056 & 1.46 & 1.371 & 1.405 & 1.421 \\
2013 & 2.527 & 2.297 & 1.725 & 2.091 & 0.985 & 2.219 & 2.016 & 2.131 & 2.286 & 2.195 & 1.686 \\
\hline
\end{tabular}

Table 3. Standardized numerical evaluation index system of logistics capabilities in Sichuan Province.

\begin{tabular}{ccccccccccccc}
\hline year & Y11 & Y12 & Y13 & Y21 & Y22 & Y31 & Y32 & Y33 & Y41 & Y42 & Y43 & Y44 \\
\hline 2003 & 1.753 & 2.406 & -1.007 & -1.015 & -1.048 & -0.978 & -2.005 & -1.25 & -1.68 & -1.654 & -1.561 & -0.839 \\
2004 & 1.012 & 0.252 & -0.957 & -0.862 & -0.913 & -0.906 & -1.433 & -1.063 & -1.195 & -1.323 & -1.274 & -0.887 \\
2005 & 1.423 & -0.591 & -0.901 & -0.867 & -0.862 & -0.843 & -0.742 & -0.827 & -1.016 & -0.985 & -0.999 & -0.775 \\
2006 & 0.247 & -1.117 & -0.894 & -0.795 & -0.721 & -0.761 & -0.051 & -0.599 & -0.628 & -0.558 & -0.775 & -0.231 \\
2007 & -0.16 & -0.364 & -0.871 & -0.588 & -0.547 & -0.593 & 0.5731 & -0.464 & -0.09 & -0.066 & -0.043 & -0.574 \\
2008 & -0.816 & -0.217 & -0.157 & -0.369 & -0.431 & -0.314 & 0.8199 & -0.221 & 0.3934 & 0.2418 & 0.2666 & -0.499 \\
2009 & -0.855 & 0.873 & 0.2047 & -0.185 & -0.235 & -0.039 & 1.0843 & 0.0633 & 0.349 & 0.4577 & 0.4709 & -0.4 \\
2010 & -0.898 & -0.134 & 0.6997 & 0.7186 & 0.8244 & 0.3247 & 0.939 & 0.3775 & 0.6651 & 0.7051 & 0.7033 & -0.058 \\
2011 & -1.2 & 0.416 & 1.0435 & 0.7964 & 0.8298 & 0.7153 & 0.5122 & 0.7776 & 0.7559 & 0.8399 & 0.835 & 0.805 \\
2012 & -0.34 & -0.409 & 1.294 & 1.295 & 1.337 & 1.464 & 0.205 & 1.368 & 1.092 & 1.079 & 1.055 & 1.239 \\
2013 & -0.168 & -1.117 & 1.543 & 1.870 & 1.764 & 1.928 & 0.096 & 1.837 & 1.353 & 1.262 & 1.319 & 2.219 \\
\hline
\end{tabular}

thereby improving the accuracy and rationality of the evaluation results. Method to determine the weight is divided into subjective weighting method, and objective weighting method This selection method CRITIC, CRITIC method proposed by the Diakoulaki [9]. He believes that the evaluation index weight is determined by two factors, one is standard deviation, which reflects the degree of variation variable; the other is the correlation coefficient, If there is a strong positive correlation between the two variables, indicating that the conflict of the two indicators is relatively low; if there is a strong negative correlation, indicating that the conflict of the two indicators is high. In this paper, a quantitative-based, while the method has been in the field of the use of synergies also more mature, with the use of this method. The basic principle of the method CRITIC

$$
C_{j}=\sigma_{j} \sum_{j=1}^{n}\left(1-r_{i j}\right), j=1,2, \cdots, n
$$

$C_{j}$ represents the degree of influence on the evaluation system, $\sigma_{j}$ represents the Standard deviation of evaluation, $r_{i j}$ represents the correlation coefficient between evaluation. The greater the value of $C_{j}$, indicating that the larger evaluation of the impact on the system, indicating the greater importance of this indicator. Objec- 
tive weight calculated as follows:

$$
\omega_{j}=\frac{C_{j}}{\sum_{j=1}^{n} C_{j}}, j=1,2, \cdots, n
$$

Based on standardized data in Table 1 and Table 2, the subsystem can be obtained by SPSS software, standard deviation and correlation coefficients, The relevant data into the Equation (4) and Equation (5), we obtain the subsystem weighting coefficients of evaluation index,

Evaluation index weight of key industries:

$$
\begin{aligned}
& w_{11}=0.11792, w_{12}=0.06016, w_{21}=0.06957, w_{22}=0.05447, \\
& w_{31}=0.23889, w_{32}=0.06607, w_{33}=0.11507, w_{41}=0.05406, \\
& w_{42}=0.06935, w_{51}=0.07722, w_{52}=0.07722
\end{aligned}
$$

Evaluation index weight of logistics capabilities:

$$
\begin{aligned}
& w_{11}=0.23998, w_{12}=0.16516, w_{13}=0.06059, w_{21}=0.05413, \\
& w_{22}=0.05578, w_{31}=0.05372, w_{32}=0.09311, w_{33}=0.04971, \\
& w_{41}=0.05502, w_{42}=0.05733, w_{43}=0.05703, w_{44}=0.05844
\end{aligned}
$$

\subsection{Calculation of Subsystem Degree of Order and Total System Synergy Degree}

Take the data in Table 2 and Table 3 into Equation (1), calculate the degree of order of the system. CRITIC method is used to derive the weight coefficient and take into the Equation (2). First calculate the degree of order of subsystems and take these data into Equation (3). Final calculation of Sichuan Province on "key industrieslogistics capabilities” system synergy degrees, are shown in Table 4.

\section{Conclusions}

By calculating the results, collaborative trends of key industries and logistics capabilities in Sichuan Province were drawn (see Figure 1 and Figure 2). As it can be seen from the figure, Sichuan Province, after the transfer of industry synergistic development system, has gone through three stages: the first phase from 2003 to 2008 shows a lower degree of synergy in $\{0.012-0.038\}$; the second phase from 2008 to 2011 shows synergistic degree rise in $\{0.012-0.112\}$ in a basic synergistic state; in the third phase from 2011 to 2013 synergistic degree continues to rise between $\{0.028-0.128\}$. Total system experienced the state from low level of coordination,

\section{Table 4. Total system synergy degree.}

\begin{tabular}{cccc}
\hline year & key industries degree of order & Logistics capabilities degree of order & Total system synergy degree \\
\hline 2003 & -0.92 & 0.017 & 0.02 \\
2004 & -0.87 & -0.37 & 0.008 \\
2005 & -0.79 & -0.28 & 0.02 \\
2006 & -0.66 & -0.46 & 0.038 \\
2007 & -0.47 & -0.26 & 0.012 \\
2008 & -0.21 & -0.22 & 0.112 \\
2009 & 0.168 & 0.079 & 0.022 \\
2010 & 0.622 & 0.127 & 0.028 \\
2011 & 0.862 & 0.243 & 0.129 \\
2012 & 1.374 & 0.495 & 0.063 \\
2013 & 1.857 & 0.624 &
\end{tabular}






Figure 2. Synergistic of the total system.

to fluctuant rise, then to basic coordination, which is in line with the basic principles and general rules of synergy. In the first phase (2003 to 2008), the degree of order in key industries gradually increased, but the logistics capability slowly declined, and increased steadily until 2008. Such as in 2006, Sichuan’s GDP was 863.78 billion yuan, which was an increase of $13.3 \%$ over the previous year; total retail sales of social consumer goods exceeded 3000 billion yuan, increasing 342.16 billion yuan, which was an increase of $14.8 \%$ over the previous year, and 2.5 percentage points higher than the average level in "China's tenth five-Year Plan" period. The development of logistics capabilities is slower, but it already has the basic logistics conditions, including a number of railway lines connected to the provinces, dozens of highways which have opened, and 120 navigable rivers; the traffic mileage has reached more than 11,000 kilometers, and open air transport has reached more than 140; a variety of transportation, Sichuan rapid transport, such as sea, land, air, rail, gradually improved various types of storage facilities. However, with the gradual rise of the economy, by 2008, the logistics industry gradually collaborated with the development of economy. In the process of economic development, the logistics industry has gradually collaborated.

In the second phase (2008-2011), the degree of order of key industries continues to rise, with larger growth rate. Affected by the Wenchuan earthquake in 2008, economic growth slowed, but the overall trend remained the same. After rapid growth in 2008, the degree of order of logistics capabilities especially in 2009 has grown rapidly, and with key industry basically reached the common development- "hand in hand" level. With the development of industry, in March 2008, Sichuan Province issued "On Accelerating the Industries to Relocate to Work", which first detailed clear support policy to deal with the industrial transfer initiatively. In 2010, China's State Council issued some government policy on "Guiding the Midwest to Undertake Industrial Transfer", which greatly promoted the development of the industry in Sichuan Province Logistics capabilities. Chengdu Shuangliu International Airport, railway container center and other major logistics infrastructure have also been put into use; adequate infrastructure greatly improved the environment of logistics development. This shows that with the increase of industrial transfer, the development of the logistics industry puts forward new demands, which needs local governments to increase investment in the logistics industry and construction. The logistics industry not only is driven by its own development, but also stimulates the rapid development of economy.

In the third phase (2011-2013), the degree of order has accelerated in the key industries, while that has decelerated in logistics capability, showing that with the late industrial transfer and the increase of enterprises, industrial chain was formed, but industrial clusters did not gain huge economic benefits. Gradually regional economic zones were formed around the core industrial development in Sichuan, such as Chengdu Economic Zone, Southern Sichuan Economic Zone, Northeast Sichuan Economic Zone, etc. Tax revenue and revenue, driven by competition in various economic zones are also growing. Local protection is not conducive to coordinated development of key industries economy. The logistics industry is also faced with new upgrades, and gradually unable to meet the new requirements of the logistics industry cluster that key industries and regional logistics have entered a new "no synergy" stage. 


\section{Suggestions}

Firstly, by playing the advantages of clustering and integration, the logistics will be able to achieve the goal of efficient allocation of resources. Under the new situation, logistics development should be adapted to the new layout after the transfers, constructing the logistics industry layout under the new situation, introducing the well-known enterprises and promoting the logistics industry and the common development of industrial clusters; meanwhile, it should also promote the key industries and logistics capabilities synergy forward.

Secondly, by playing the advantages of industrial clusters, the logistics will be able to promote the formation and development of the industrial chain. In the context of industrial transfers, the logistics will not only give a positive response, but also build the supporting industries, in order to create specialized industry chain. Anyhow, the formation of industrial clusters is the direction in response for the transfer of industries in Sichuan Province.

Thirdly, the cooperation mechanisms should be established. The regional economic joint conference system from the provincial level, among various economic zones in Sichuan Province should be coordinated and improved to promote cooperation and communication. Facing with the industrial transfers, clearly industry positioning within each economic zone should be done. Besides, the industrial should follow collaborative development, which is in order to complement each other, instead of vague economic zone positioning, resulting in overlapping industries and waste of resources.

\section{Acknowledgements}

This paper is sponsored by Hebei Province Department of Education (SQ141122).

\section{References}

[1] Akamatsu, K. (1962) A Historical Pattern of Economic Growth in Developing Countries. The Developing Economies, 1, 3-25. http://dx.doi.org/10.1111/j.1746-1049.1962.tb00811.x

[2] Vernon, R. (1966) International Investment and International Trade in the Product Cycle. The Quarterly Journal of Economics, 80, 190-207. http://dx.doi.org/10.2307/1880689

[3] Kojima, K. (1978) Direct Foreign Investment: A Japanese Model of Multinational Business Operations. Croom Helm, London.

[4] Arvis, J.F., Mustra, M.A., Panzer, J., Ojala, L. and Naula, T. (2007) Connecting to Compete: Trade Logistics in the Global Economy. World Bank, Washington DC. http://www.worldbank.org/lpi

[5] Christopher, M. (2012) Logistics and Supply Chain Management. Pearson, UK.

[6] Hui, Y.R. and Dong, Q.L. (2008) Sustainable Development Evaluation for Logistics Industry Based on Data Envelopment Analysis. Journal of Beijing Jiaotong University (Social Sciences Edition), 3, 011.

[7] Liu, L.-Z. (2012) Analysis of the Relationship between QinHuangDao Port Logistics and Economic Growth. Advances in Information Sciences \& Service Sciences, 4, 105-114. http://dx.doi.org/10.4156/aiss.vol4.issue4.13

[8] Xu, T.T., Peng, J.L. and Ding, F. (2013) Linkage Relationship between Port Logistics and Regional Economy Based on Eviews Software. Journal of Software, 8, 971-978. http://dx.doi.org/10.4304/jsw.8.4.971-978

[9] Diakoulaki, D., Mavrotas, G. and Papayannakis, L. (1995) Determining Objective Weights in Multiple Criteria Problems: The CRITIC Method. Computers \& Operations Research, 22, 763-770.

http://dx.doi.org/10.1016/0305-0548(94)00059-H 